\title{
Jingdezhen Ancient Site Landscape Architecture Form Elements
}

\author{
Zhihua Xu \\ School of Jingdezhen ceramic institute of design art, Jingdezhen 333403, China
}

Keywords: Jingdezhen, the ancient site, architectural landscape.

\begin{abstract}
Jingdezhen plate of longgang ancient site construction residential, porcelain manufacture in a body, thus the layout there are both the layout of the traditional Chinese characteristics and its local porcelain making unique form. First in large area overall planning to control the construction base location, obtain the composition of harmonious and unified and orderly rhythm. And according to different space have different building pattern, the residential area USES the structure and layout of Chinese traditional courtyard house and put your hands up, and porcelain making in construction according to the particularity of the function USES the unique form. But in addition to meet their porcelain making needs, the overall trend still the structure of the traditional courtyard style.
\end{abstract}

\section{Seek common ground while reserving differences of the ancient site building landscape overall layout}

Jingdezhen local-style dwelling houses building features are very compact, small villages, a neighborhood, but the whole give a person with a strong appeal. This is due to the jingdezhen is located in the mountains all around, jingdezhen people because of the influence of the symbiosis of group consciousness, they need agglutinate force against the nature and the outside world, it is this ideology formed under the construction of compact sense; Also because of mountain many more trees, wood and stone used to build houses is inevitable. At least two hundred years ago in jiangxi province can skilled build brick hybrid structure house, understand give full play to the material performance and the way of selecting rational structure, for jiangxi mountainous area, processing of wood is more easy, easy and flexible to use wooden room between also more, wood structure is better than cold hard brick wall make a person feel very warm.

In addition, jingdezhen is the place that merchants and craftsmen concentrated activity, is China's only famous for its production of porcelain town in one thousand. Jingdezhen in a porcelain making handicraft production and support the development of a city, and to maintain a town nearly one thousand years of prosperity and decline. The change of the market and the formation process silently recorded the history of its development. Jingdezhen because in ancient belongs to the commercial city of an open, here gathered a lot of other areas do porcelain and ceramics businessman earning a living, so is a population of a number of big city, so to speak. Migrant population assembled jingdezhen is not only promoted the development of the porcelain industry, the humanities, architecture, customs and so on various aspects are has a great influence. This recorded in many ancient articles and stories, such as "floating point than mountains, jingdezhen, is a metropolitan city south also, electronic ceramics, five mixed, department with josh MCE said sheng yi." (Chen Yuji); "The float saddle county annals" : "HaoShang merchant, salty together; in its numerous rich people, in a province." Blue pu in the jingdezhen TaoLu cloud: "how, meriton ten provinces, the most hub on shoulder of moab, the quartet, pale even scales, wanhu thickened, cheng jiang metropolitan is right." The characteristics of these four mixed jingdezhen architectural features have been formed, in addition to the characteristics of local also combines the construction characteristics of all over the country. 


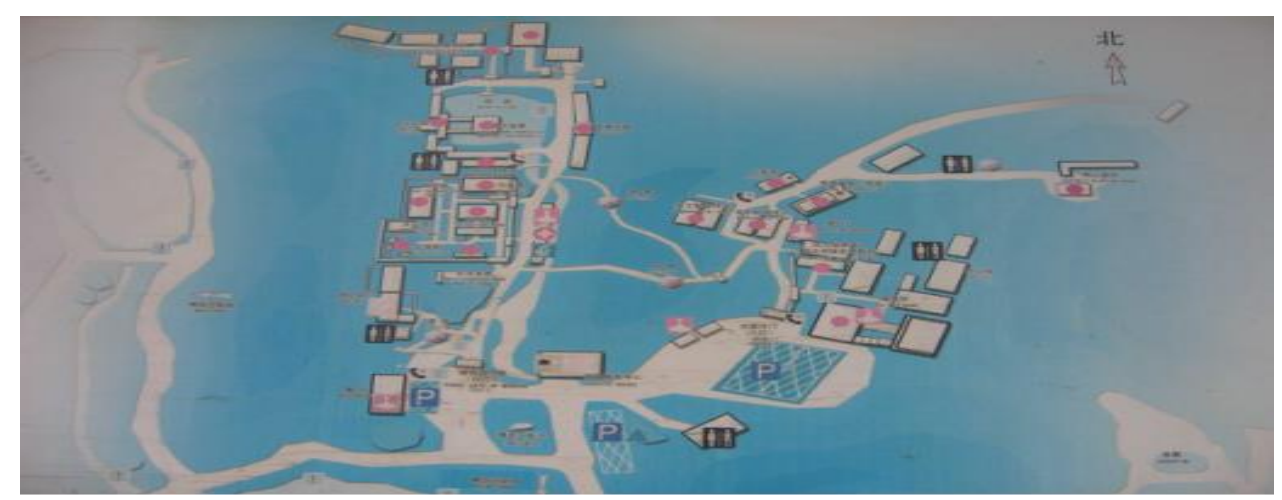

Figure 1 Architectural layout plane

The architectural features in dish of longgang ancient site in the landscape plan can be fully reflected. (figure 1) the construction general layout is not only convenient for people's living labor needed, more from the spiritual embodiment of acquired longgang overall layout of the particularity of the ancient site. To show adequately, humanistic spirit to achieve better higher request, make more humane and scientific. Plate of longgang town of kiln, the ancient site distribution of handmade ceramic workshops, ancestral temple, such as residential buildings, residential, porcelain manufacture in a body. The following will analyze from these aspects.

Traditional jingdezhen porcelain making workshop factors and its culture is harmony, including a variety of related events and people's conception and complex, it includes ecological civilization, geographical environment, ceramic raw materials, transportation, time history, and social stratification. Traditional porcelain making workshop is not a pure thing that exist in a closed space, its culture, religion and social space, economy, politics, science and technology and even the natural ecology has. So the study of the formation of traditional jingdezhen porcelain making workshop must put it in a certain natural environment, social organization, which is very important to understanding the cause of the workshop.

\section{The natural climate impact on traditional porcelain making workshop building structure}

Well day, sometimes to have spirit, material has the United States, workers have a smart", and "the husband's adult, and the heavens and the earth and its virtue, and the moon and the bright, with four or its sequence......". The importance of climate for traditional porcelain making architecture. Jingdezhen locates the geographical position of 57 ' 42,117 degrees east longitude 116 degrees: 28 degrees north latitude 44', 29 degrees 56, belongs to subtropical monsoon climate. First of all, is China's forming, because of the influence of the monsoon climate, the winter cold, summer heat, spring, summer, rainy, autumn and winter drought. Dominant wind direction for south or south by east, at the same time, according to the different times of the year light, rainfall and wind direction, the particularity of porcelain production molding process, and give attention to two or morethings craftsmen operation habit, so need to consider when building workshop to resist the cold climate, avoid rain, keep out sunshine point-blank, block the wind and other conditions. Based on the grasp of the relationship between climate and production, people will workshop sits, stagger the inclined column, the introversion layout, first of all, according to the craftsman to the identity of the master-slave and are important and minor technology, has the production function of ethics; Secondly because suitable for ceramic production of the division of labor cooperation, to technical secret quiet private space and the space aggregation function; Its internal open again watching out for each other, the external independent closed with protective ring who function; Finally have the function of climate regulation. At the same time, control the height of the building size, the distribution of strewn at random discretion, so that is conducive to natural lighting, ventilation, convection, air circulation, water cycle. Make full use of natural light is beneficial to human body health, improve work efficiency, make full use of the natural heat source and cold source heating and cooling; Make full use of natural ventilation cooling, dehumidification, improve air quality. 
Construction also concerns to the jingdezhen kiln room climate characteristics: high slope steep roof and eaves, low eaves can prevent the rain drifting into the room: in the middle of the house groove part broadening layer eaves roof projection area increase, coupled with a high roof and small Windows, make the kiln gas convection inside the room, to avoid the room temperature is too high, the overhead of the floor slab, moistureproof, effectively to fuel dry guarantee ceramic firing effect, also considering the influence of the monsoon, and the chimney design into high and low similar to the shape of a "nib", can prevent the northwest wind flow backward into the chimney lead to the failure of porcelain firing.

\section{Topography influence on traditional porcelain making workshop building structure}

Jingdezhen landscape more for low and middle mountain, the mountain is covered with rich forest resources, wood grain to provide a steady stream of fuel burning kilns room: the surrounding areas in the rock containing the China stone, porcelain clay, glaze fruit, such as mineral resources, for the production of ceramic provides a wealth of raw materials; River densely formed within the territory of the natural transportation system, fuel, raw materials, transportation and distribution provides the impetus of ceramic products, to the use of these resources fully the development of jingdezhen maintain the natural ecological system. Jingdezhen ceramic craftsmen under special landform system porcelain workshop will choose the suitable flat building: in accordance with the slope of the mountain built bank kiln: on the space form the forest, mineral, mill, kiln, porcelain, wharf of vertical distribution pattern.

The spatial distribution pattern of use from the top of the mountain to cut wood, a kiln mining minerals along a river or by choose wood under the foot of porcelain blank forming in the workshop, arrived after the completion of kiln house on fire, saves the transportation cost of fuel, raw material also shorten the transportation distance, formed the ancient porcelain making "assembly line" type working mode. Through ecological and energy exchange, individual and collective collaboration, make the production smoothly and orderly, a balanced environment comfortable effect. Local characteristics and cultural characteristics, create a suitable for people to produce low energy consumption, high practical construction.

\section{Local material impact on traditional porcelain making workshop building structure}

Is dependent on specific building materials and any building built according to the material that conforms to the characteristics of technological process. Therefore, materials, and the difference of construction technology will surely affect the building style and structure. Traditional jingdezhen porcelain making workshop, structure and style of the kiln room also affected by the building materials and technology, has a clear regional architecture.

Jingdezhen for red soil and yellow soil land, such as pine, fir wood, such as the jingdezhen is still at the low productivity of small-scale peasant economy, living a life "backer has mountain, draft on water", craftsmen to follow the natural law of local materials, adjust measures to local conditions, in addition to the eaves tiles of the roof through simple processing, most of the rest of the building materials are the original natural materials. Masonry kiln kiln brick is used in the room by the local soil and far-flung internal structure, the use of the local is rich in timber construction, twin kiln is taken from the field of mud, mud brick kiln after a period of time after the use of being built, disused kiln bricks used to build the workshop foundation, paving, etc.

\section{Conclusion}

To sum up, jingdezhen ancient site the elements of landscape architecture formed mainly adjust measures to local conditions, fully in line with the well remember days, sometimes to have spirit, there is a beauty, there are four zhao opportunely, therefore the ancient site of jingdezhen landscape not only 
accomplish the reasonable use of resources, reduce energy consumption and reduce the pollution to the environment, which fully reflects the characteristics of ecological landscape.

\section{Acknowledgements}

Zhihua $\mathrm{xu}$, male, $\mathrm{PhD}$, postdoctoral fellow, university of jingdezhen ceramics backbone teachers, research direction: environmental art design and theoretical study, environmental ceramic art, the Chinese stone inscription art history research. This fund projects: 1, jiangxi social sciences planning project of the intangible cultural heritage tourism landscape design research - jingdezhen ancient kiln heritage tourism landscape, for example, the number is: 15 ys27. 2, in jiangxi province cultural department scientific research project of the jingdezhen culture industry construction under the ancient site of the landscape design research, number is: YG2014177. 3, humanities and social science in colleges and universities in jiangxi province project the regionality of humanities landscape design - to jingdezhen ancient kiln building landscape design as an example, and Numbers for: GX201529.

\section{References}

[1] Xiu-mei wu "system of inheritance and change: the republic of China jingdezhen porcelain development research, Beijing: guangming daily press, 2012.

[2] Various ge armoured with "design art ten speak" jinan: shandong pictorial publishing house, 2006.

[3] Liang sicheng "Chinese architecture" Beijing: China building industry press, 2005.

[4] Dai Wu three "the well after the jinan: shandong pictorial publishing house, 2005.

[5] Chang Huaisheng building environment psychology, Beijing: China building industry press, 1990.

[6] Liu Duizhen "Chinese ancient architectural history" Beijing: China building press, 2001.

[7] Lixin li "the design of art research methods" nanjing: jiangsu phoenix publication medium group fine arts publishing house, 2010. 